\title{
DICK SILVA NO MUNDO INTERMEDIÁRIO: A EXPERIÊNCIA DE MORTE NA NARRATIVA JUVENIL
}

\author{
DICK SILVA IN THE INTERMEDIARY WORLD: THE DEATH \\ EXPERIENCE IN THE YOUTH NARRATIVE
}

\author{
Aline Barbosa de Almeida* \\ João Luís Cardoso Tápias Ceccantini **
}

\begin{abstract}
Resumo: A morte é uma experiência com diversas conotações, transpondo-a para o campo literário seu significa amplia e transcende nossa ideia de realidade, causando um estranhamento e nos permitindo vivenciá-la a partir de outros contextos. Nesse sentido, pretendemos abordar a temática da morte como elemento fruidor do romance juvenil Dick Silva no mundo intermediário (2016) do escritor gaúcho Luís Dill a partir de concepções estéticas da cultura de massa. Assim, temos como aporte teórico as ideologias de Adorno e Horkheimer (2002) quando se refere à "barbárie estilizada"; Macdonal (1971) sobre a ideia de alienação e homogeneização do público leitor; Morin (1977) no que diz respeito à integração da cultura de massa, Eco (2001) sobre os desafios estéticos que a cultura mass media representa nas produções literárias juvenis e Candido (1999) apropriando-se da Literatura como ferramenta indispensável para a formação humana.
\end{abstract}

Palavras-chave: Romance juvenil. Luís Dill. Morte. Estética.

\begin{abstract}
The death is an experience with diverse connotations, transposing it to the literary field means broad and transcends our idea of reality, causing a strangeness and allowing us to experience it from other contexts. In this sense, we intend to address the theme of death as a fruitive element of Dick Silva in the intermediary world youthful novel (2016) of the writer Luís Dill, based on aesthetic conceptions of mass culture. Thus, we have as theoretical support the ideologies of Adorno and Horkheimer (2002) when it refers to "stylized barbarism"; Macdonal (1971) on the idea of alienation and homogenization of the reading public; Morin (1977) regarding the integration of mass culture, Eco (2001) on the aesthetic challenges that mass media culture represents in youth literary productions and Candido (1999) appropriating Literature as an indispensable tool for human formation.
\end{abstract}

Keywords: Youthful Novel. Luís Dill. Death. Aesthetics.

\section{Um Escritor Multifacetado}

Luís Augusto Campello Dill, escritor contemporâneo, nasceu em abril de 1965 em Porto Alegre, formou-se em jornalismo pela Pontifícia Universidade Católica (PUC) do Rio Grande do Sul e possui Pós-graduação Lato Sensu em Literatura Brasileira. Enquanto jornalista atuou na assessoria de imprensa, jornais, rádio e televisão. Atualmente o escritor é produtor executivo da Rádio FM Cultura Gaúcha e fundou em 2017 a Editora Casa 29 com intuito de ampliar a formação leitora da sociedade.

A carreira como escritor teve estreia em 1990 com a obra A caverna dos Diamantes, tal obra é uma novela policial juvenil e que já traz as características do seu projeto estético no que se refere à produção literária. Luís Dill tem mais de cinquenta livros publicados e de acordo com Martha (2015, p. 213) é o escritor que mais retrata a violência urbana, pois nas suas diversas produções como contos, romances, novelas,

\footnotetext{
* Doutoranda em Letras na linha de pesquisa Literatura e vida social do programa de Pós-Graduação em Letras da Universidade Estadual Paulista Júlio de Mesquita Filho (UNESP/ASSIS). E-mail: ab.alinealmeida@gmail.com

** Professor Doutor da Universidade Estadual Paulista Júlio de Mesquita Filho (UNESP/ASSIS). E-mail: ceccantini@uol.com.br
} 
poemas e narrativas para adultos e jovens, desenvolve temas polêmicos, "considerados tabus pela sociedade", mas com a sutileza de não ultrapassar "os limites do universo dos jovens leitores".

Além disso, o escritor gaúcho carrega importantes premiações literárias, recebeu o prêmio Açorianos na categoria conto pelo livro Tocata e fuga (Bertrand Brasil) e na categoria juvenil com os livros De carona, com nitro (Artes e Ofícios) e Decifrando Ângelo (Scipione). Também recebeu o prêmio Livro do Ano da Associação Gaúcha dos Escritores na categoria poesia com o livro Estações da poesia (Positivo). Foi laureado em terceiro lugar do prêmio Biblioteca Nacional na categoria juvenil com o livro $O$ estalo (Positivo). Somado a esse histórico a Fundação Nacional do Livro Infantil e Juvenil deu a alguns de seus títulos o selo Altamente Recomendável.

Dentro desse contexto, compreendemos que os romances de Luís Dill configuralhe um caráter singular, multifacetado e intermediador, pois transita em diferentes temas e experimentações da estrutura textual, além do trabalho editorial que engloba suas produções. O papel social que desenvolve em relação aos jovens é vinculado ao trabalho narrativo, uma vez que o escritor contempla as inquietações do universo juvenil (primeiro amor, família, amizade, violência, assassinato, morte, entre outros aspectos que enaltecem o contexto do jovem) dando ênfase ao gênero policial, que estimula o leitor a ser um cúmplice do autor, ampliando, assim, a carga semântica da obra.

Os discursos sociais e culturais trabalhados na narrativa de Dill propõem aos receptores um jogo de caça, Langlade (2013) menciona que a porção lúdica da cooperação entre autor e leitor está para o domínio e respeito das regras, bem como o consentimento ativo dos jogadores. É preciso, então, dar sentido à metáfora do campo da caça furtiva, por isso que:

[...] a "caça furtiva" é precisamente não respeitar as regras da caça aristocrática, da caça que se exibe em plena luz do dia em um gênero de espetáculo mundano e gratuito, a "caça furtiva" significa se apoderar secretamente da presa textual, frequentemente em meio a trevas, com o concurso de armadilhas ou procedimentos pouco regrados. [...] A "caça furtiva" é ocupação de um sujeito leitor transgressor. (LANGLADE, 2013, p. 34).

Pelo viés do mistério, do suspense e das tragédias Dill chama seu leitor para essa caça furtiva, instigando o leitor a assumir uma postura, na maioria das vezes, de um detetive. A ambientação fechada, as digressões construídas no diálogo entre personagens, bem como a linguagem trabalhada são aspectos textuais que enveredam o leitor às dualidades da significação do texto e da trama que irá suceder.

Além desse aspecto, há uma preocupação estética em sua produção. Em uma entrevista feita pela Revista Samizdat em 2011, o autor foi questionado sobre as especificidades do gênero policial, bem como o que se precisava ter em mente ao escrever para o público infanto-juvenil diante das exigências do mercado editorial. Frente a isso o escritor expressa a seguinte opinião:

Não vejo grandes diferenças entre literatura juvenil e literatura adulta. Sequer gosto dessas segmentações. Para mim é tudo literatura. O que tomo como regra para mim é evitar palavrões e cenas muito explícitas em termos de sexo e de violência quando escrevo livros destinados aos jovens. Penso que o gênero requer ritmo, boa estrutura narrativa, ação e, sobretudo, qualidade. (SAMIZDAT, 2009) 
O autor está inserido em uma era que a Indústria Cultural dita a maior parte das produções literárias, por questões mercadológicas e políticas, difundindo uma cultura de massa que ressalta uma estética diferenciada e pouco apreciada pelos acadêmicos, os quais prezam por uma cultura culta e, portanto, esta deve prevalecer e sobrepor-se em relação à outra. Segundo Macdonald (1971) a cultura de massa não propõe estímulos reflexivos sobre os leitores, já que a mesma é de fácil apreensão, porque não tem estética e não possui critérios de avaliação. Há, portanto, uma homogeneização do público, por meio dos produtos difundidos da Indústria Cultural, que provoca uma alienação, já que o indivíduo não é capaz de reconhecer-se em sua individualidade, mas a partir de um coletivo solitário, que propaga sempre "mais do mesmo".

É dentro desse contexto que Luís Dill se sobressai e integra-se a um sistema editorial contemporâneo sem perder seu estilo. Ele não diferencia as dificuldades estéticas da Literatura construída para jovem e para o adulto. O escritor mostra uma consciência de que a produção de um texto literário requer cuidados, independente da faixa etária a que se destina a obra. Quando escreve para os jovens preza por uma linguagem simples e construções imagéticas que não violam o limite de vivência do jovem receptor. A preocupação de dar ritmo a narrativa, criar uma boa estrutura e prezar pelas qualidades, nos revela que o escritor contemporâneo transcende uma esfera que a Indústria Cultural coloca como padrão.

Ele não deixa de contemplar o cotidiano, aquilo que é comum ao jovem, porém o trabalho com a linguagem, mesmo de maneira simples, contempla vários desafios e convida o leitor para fruir sobre as ações de determinado personagem, quando o envereda em uma temática polêmica através de uma linguagem metaforizada e impulsionando-o a pensar na vida. Partindo dessa premissa, o escritor consegue transpor a realidade social do jovem (campo externo) na estrutura textual (campo interno) de suas obras. Desse modo, entendemos que:

[...] não é verdade que os meios de massa sejam estilística e culturalmente conservadores. Pelo fato mesmo de constituírem um conjunto de novas linguagens, têm introduzido novos modos de falar, novos estilemas, novos esquemas perceptivos (basta pensar na mecânica de percepção da imagem, nas novas gramáticas do cinema, da transmissão direta, na estória em quadrinhos, no estilo jornalístico...). Boa ou má trata-se de uma renovação estilística, que tem, amiúde, constantes repercussões no plano das artes chamadas superiores, promovendo-lhes o desenvolvimento. (ECO, 2001, p. 48).

Um produto da cultura de massa, destinado ao entretenimento, pode traçar desafios estéticos ao fruidor, veiculando valores originais. Depende, assim, do projeto estético do artista e como ele transmuta esse fenômeno. Luís Dill demonstra ser plenamente um escritor em sintonia com sua época, em obras como Todos contra D@nte (2008) e Olhos Vendados (2007) o escritor apropria-se, na primeira, de uma estrutura influenciada pelas redes sociais; na segunda, emprega um tom jornalístico na linguagem, valendo-se de cartas vinculadas a um programa de rádio. Assim, ele procura diferenciar, a cada obra, a maneira de estimular a fruição do leitor juvenil e busca diversos recursos estéticos no que concerne seu modo de narrar. 
É dentro desse contexto que podemos afirmar que o escritor gaúcho sabe explorar a tradição erudita, mas sem se distanciar das tendências estéticas atuais. Ele consome a realidade e a transforma de acordo com seu projeto estético e o público que tem como referência. Candido (2006, p. 84) diz que a literatura é um sistema vivo de obras, "agindo umas sobre as outras e sobre os leitores; e só vivem na medida em que estes a vivem, decifrando-a, aceitando-a e deformando-a". A ideia de adaptação e/ou reprodução nas obras para jovens de Dill encaixa-se nessa afirmação de Candido, tendo em vista que o escritor, antes de colocar a técnica em prática, é, sobretudo, um leitor, que recepciona outras obras e o mundo.

Partindo desses pressupostos iremos analisar o romance juvenil Dick Silva - no mundo intermediário (2016) de Luís Dill no intuito de verificar algumas tendências estéticas da contemporaneidade vinculadas à indústria cultural e como tal estética atrai o leitor juvenil.

\section{Uma Centelha}

O romance juvenil, Dick Silva - no mundo intermediário publicado em 2016 pela Editora Pulo do Gato. O referido romance possui onze capítulos e tem uma narrativa linear, que conta as peripécias de um adolescente que acorda na Sala de Interrogatórios do Departamento de Capturas do $10^{\circ}$ Distrito. O inusitado é que a personagem, Roneldick Samuel da Silva, não sabe o motivo de estar ali e nem como chegou. Notamos isso quando:

Ele estava dormindo na sala de interrogatórios. Tinha quinze anos, corpo franzino. Era alto para a idade. A cabeça deitada em cima dos braços cruzados sobre a ampla mesa de madeira escura. Um fio de baba escorria pelo canto da boca. Vestia jeans e camiseta branca. Tênis esportivos sem meias. [...] Nenhum ruído penetrava ali, como se o mundo exterior não existisse ou simplesmente não fosse capaz de ferir o zumbido irritante do silêncio. Nada indicava a passagem do tempo nem a presença de outro ser humano. [...] Viu a superfície lisa, escura, tateou-a com a ponta dos dedos. Aí puxou o ar pelo nariz afilado. Encheu os pulmões, sem pressa. Sentiu o ar espalhar-se por seu organismo, passou a língua pela baba em ato automático. Inspirou de novo, desta vez com mais força. O oxigênio começou a dar-lhe foco, precisão. Sinapses ainda imprecisas foram construindo a pergunta: "Que lugar é esse?" [...] "O que eu tô fazendo aqui?". (DILL, 2016, p. 07-08).

A presença da instância narrativa heterodiegética com foco narrativo na personagem leva o leitor a ser guiado pelas percepções de Dick. No início o narrador nos apresenta a personagem de forma direta, assim temos a construção da mesma por um viés metonímico, por sua idade (quinze anos) e vestimenta (jeans, camiseta branca, tênis esportivo) que o denuncia como um todo, neste caso, um adolescente. Na narrativa de Luís Dill a figura do jovem como personagem central é um elemento recorrente. Essa apropriação é notória, dado ao fato de que o escritor tem como ponto de partida o público juvenil, assim, esse jogo verossímil diz respeito à necessidade de identificação do sujeito leitor com a obra. Segundo Morin (1971) esse é um aspecto integrador da 
cultura de massa, visto que essa manifestação da cultura pode ser vista como integrante na formação de identidade do homem contemporâneo, ou seja, os elementos do cotidiano, bem como as inquietações juvenis, presentes no respectivo romance trazem essa atmosfera atual configurada na caracterização da personagem.

Os questionamentos “Que lugar é esse?” e "O que eu tô fazendo aqui?" que Dick se faz diz respeito à Sala de Interrogatórios, um lugar fechado, que não entra som algum, não mostra nenhuma presença humana, nem mesmo a passagem do tempo. Luís Dill nos dá, a princípio, um lugar fechado, claustrofóbico e quieto. Um ambiente angustiante para um jovem que lida com o frenesi da liberdade, da bagunça urbana, do barulho sincronizado da vida em sociedade e do tempo infindo. À medida que Dick desperta, a Sala de Interrogatórios vai ficando mais nítida, notamos isso na seguinte passagem:

Sacudiu a cabeça de leve. A visão acostumou-se ao ambiente, à luminosidade, aos objetos por ela destacados com certa fúria. Inspecionou cada centímetro da Sala de Interrogatórios. E ele ainda não sabia que se tratava de uma Sala de Interrogatórios. Tinha algo muito errado. Mas ele não conseguiu identificar de imediato. No íntimo, teve a certeza de que era óbvio ao extremo, como saber o próprio nome ou acertar o resultado da soma dois mais dois. No entanto, nada lhe ocorria, mesmo repetindo o reconhecimento visual. Fixou-se na porta maciça e ela apareceu-lhe própria de cofres. E a falta de maçaneta the deixou bastante intrigado. "Será que eu tô trancado aqui dentro? Num cofre?" -Epa...

Nesse momento, ouviu ruídos metálicos vindo justamente da porta. [...] Viu o homem entrar. Alto, corpulento, sessenta e poucos anos. Vestia terno cinza e gravata preta. Camisa branca. O chapéu, também cinzento. Sapatos pretos empoeirados. Com o cotovelo bateu a porta espessa. Ela se fechou com outro cléc, mais sonoro. [...] Foi quando o menino se deu conta do óbvio: tudo estava em preto e branco. (DILL, 2016, p. 09).

O narrador vai produzindo uma imagem da Sala de Interrogatórios a partir do foco visual de Dick, que de imediato encontra-se desfocado. Conforme a luminosidade, advinda da janela e da lâmpada presa, "que tornava o ambiente cru e hostil", a personagem vai encontrando o foco e tem uma visão melhor do espaço. É um efeito imagético instigante para a semântica do texto, pois reverbera a percepção de estarmos sendo guiados por uma câmera, configurada no movimento do olhar da personagem, do recuo do foco, bem como de um filtro de cor em gradação monocromática. Ocorre, assim, uma representação da linguagem imagética fotográfica em preto e branco, que mais à frente iremos abordar de forma detalhada.

Dado ao contexto social e mercadológico, o escritor contemporâneo precisa abrir mão de novas técnicas de reprodução, afim de que o produto engate no reconhecimento econômico da editora. É natural que nesse processo os artistas tornem-se influenciados pelas ferramentas da tecnologia, experimentando a linguagem imagética, advinda da apreciação da TV, do cinema e da fotografia na Literatura. Adorno e Horkheimer (2002, p. 06) mencionam que a necessidade de novos efeitos para atrair o público imprime na indústria cultural uma identidade própria de linguagem, com um léxico e sintaxe própria. Desse modo, esse novo estilo “é, um sistema de incultura ao qual se poderia 
conceder certa unidade estilística, enquanto ainda tem sentido falar em barbárie estilizada".

Os respectivos teóricos possuem uma visão generalizada sobre a influência da indústria cultural na arte, tanto que Umberto Eco os denomina de "apocalíticos". É interessante notar que no Brasil, desde a década de 70, esses elementos constitutivos da imagem (TV, cinema, dispositivo de computadores) vêm interferindo na apropriação da realidade através da Literatura, assim as técnicas de reprodução muda o modo como produzimos a literatura e a fruímos, isto é, de acordo com Pellegrini (1999).

Partindo desse princípio, podemos notar que Luís Dill é influenciado por esses elementos, mas ele não cai nos ditames de uma "barbárie estilizada". De forma sutil e gradativa, nos revela as imagens do espaço por meio do olhar de Dick. No primeiro capítulo a personagem, antes de ter o foco total do ambiente, tem uma ação performática de abrir os olhos: "Ele abriu os olhos a custo, pálpebras pesadas" (p. 07); "Tornou a abrir os olhos". (p. 08). É nesse entrar e sair da luminosidade nos olhos de Dick que o escritor cria o todo do espaço, ação que se torna um desafio estético para o fruidor, já que essa constituição do local em preto e branco anuncia uma significação do estado orgânico e emocional da personagem.

Portanto, a qualidade de escrever para jovens que Dill preza pode ser vista nesse cuidado ao criar um espaço com percepções tão singulares que nos diverte. $\mathrm{Na}$ concepção de Eco (1985, p. 48) o divertimento não está associado a desvio de problemas, neste caso, o "di-verter", como denomina. Esse divertimento é marcado pela aprendizagem, em que o leitor aprende "algo sobre o mundo ou algo sobre a linguagem, eis uma diferença que marca diferentes poéticas da narratividade".

Outro ponto importante a ser explorado no romance é a surpresa de Dick Silva está vendo tudo em preto e branco. Possivelmente, esse tom monocromático, remete ao estado da personagem, já que o mesmo surpreende-se ao saber que está morto e sofre de uma estranha amnésia.

-Morreu, meu jovem. Simples assim. Não há nada a ser feito. Sinto muito.

E só.

Não forneceu detalhes. De acordo com as regras, não cabia a ele contar tim-tim por tim-tim. O recém-chegado deveria lembrar por si, sem auxílio de pormenores.

- Mas... senhor...

$\mathrm{Na}$ tentativa de quebrar a tensão na Sala de Interrogatórios, o tenente observou:

- Ora, vamos, garoto. Todo mundo morre.

- Mas...

- Você não ia querer viver para sempre, estou certo?

- É que...

- Claro, é meio chocante no começo. Eu entendo. Comigo mesmo foi assim.

O menino enxugou a palma das mãos no jeans.

- Quer dizer que o senhor...?

- Sim, garoto. Correto. Estou morto. Lembra-se da srta. McCartney, aquela belezura espevitada? Também está morta. Porque aqui, meu jovem, estamos todos mortos.

Aí a sala se fechou em negro. Roneldick penetrou em um mundo vazio, morno e sem memória. (DILL, 2016, p. 23). 
O discurso direto, os períodos curtos, bem como os recursos da pontuação (reticências e interrogação) propagam um tom humorístico, em que Dill trabalha a temática da morte de maneira leve e empolgante, já que coloca a personagem, através do narrador, em uma situação de incerteza e curiosidade sobre seu estado de vivomorto. Há aí uma configuração de um paradoxo, pois vida e morte coexistem no mesmo âmbito. Notemos que Dick possui todas as faculdades de um vivo, ele respira, consegue ver, soa, sente dor, mais a frente na narrativa seu paladar e olfato serão aguçados; no entanto, diante disso, ele ainda é um morto e sem memória.

A amnésia da personagem é recorrente na narrativa e o narrador não nos revela a história do garoto e nem como foi assassinado. Assim, Dick se esforça para lembrar, mas a única pista que tem, é que chegou ao necrotério da Cidade e está sendo acusado de assassinato, daí o motivo da sua presença na Sala de Interrogatórios. Mesmo o tenente Duran y Toledo mostrando-lhe as fotos das vítimas e interrogando como Dick as matou, o jovem não lembra e declara-se inocente.

Notamos que o garoto não possui a faculdade de lembrar, por isso há uma dualidade, entre aquilo que se mostra presente pela sua consciência tátil e a situação insólita de estar morto e sem memória. De acordo com Morin (1997) a zona de incerteza entre o cérebro e o ambiente também é a zona de incerteza entre a subjetividade e a objetividade, entre o imaginário e o real, e fica ainda mais aberta pela existência da brecha antropológica da morte e pela irrupção do imaginário na vida. Entende-se que a memória é construída através de imagens, sendo assim, a associação do imaginário e da imagem é um modo de olhar o mundo e conhecê-lo. Dick, em função da amnésia, ainda não consegue ter esse imaginário pleno, mas irá reconstruí-lo em uma nova vida em estado de morte, já que voltar à vida não lhe é mais possível.

É nesse contexto que o tenente descobre que a morte de Dick foi acidental, o garoto não era para estar morto e o verdadeiro culpado estava à solta na cidade dos mortos. Sendo assim, o jovem entra em uma aventura atrás de descobertas e do assassino. Ele é integrado na sociedade e aos poucos vai adaptando-se aquele novo estado. Nomeia a cidade de Mortopólis e a partir da sua nova experiência começa a significar aquele mundo, em que o tempo é também uma incógnita.

Dentro dessas novas experiências Dick descobrirá que é possível desenvolver laços de amizade e amor. Essa situação se dá através do contato com Bernadete, uma jovem garçonete do Lancho-Nat.

Era a garota mais linda que já tinha visto na vida.

E na morte.

[...] Será que a Megan Fox morreu e também veio parar aqui. Ele também se admirou por lembrar o nome da atriz. Mas nada o assombrou mais que os olhos da moça.

Eram azuis.

[...] - como é seu nome? O menino perguntou, mesmo se odiando por ter feito pergunta tão óbvia. Queria ouvi-la dizer "Fox. Megan Fox". Não conseguia parar de pensar na cena em que ela verifica o motor enguiçado do velho Chevy no filme Transformers. "Acho que minha memória está voltando". (DILL, 2016, p. 75-80).

Dick começa a recuperar sua memória a partir de experiências que lhe remete semelhanças no mundo dos vivos, como por exemplo, a referência da atriz Megan Fox no filme Transformers. A personagem tem a percepção de que essa nova vida irá lhe 
render vivências prazerosas e ainda poderá descobrir os encantos de ser jovem. A morte, dentro dessa visão, configura-se como divertida e desafiadora. Além disso, Dick consegue ter uma centelha de cor através dos olhos azuis de Bernadete. Esse é um ponto importante na narrativa, pois Dick, aparentemente, é o único com essa capacidade de enxergar as cores em Mortópolis, vejamos:

- Sério? Não está enxergando tudo preto e branco?

- Sim, tudo, menos seus olhos.

Bernadete aguardou ele acrescentar ou confessar algo.

- Estranho. Tem certeza, Dick? Não é uma brincadeira sua? - seu rosto se transformou. Saiu do cordial e foi até o intrigado. Ela se lembrava do azul.

- Tenho certeza. Azuis, lindíssimos. Não! - tentou se corrigir. - Quer dizer... eu só... (DILL, 2016, p. 89).

- E meus olhos, Dick? Continuam azuis?

- Sim. Azuis e lindos.

$[\ldots]$

- Existe uma história - tentou sorrir, afastar o mal-estar. - Talvez seja mais uma lenda.

- Lenda?

- Sobre isso - ela apontou vagamente para seus olhos. - Sobre alguém enxergar colorido nesse mundo. (DILL, 2016, p. 128).

Dick consegue ver essa centelha da cor azul em uma Mortópolis em preto e branco, nos parece que o garoto é predestinado a grandes feitos, no entanto, o narrador nos deixa em estado de curiosidade, já que a história da lenda não será explorada na narrativa. $\mathrm{O}$ contato com a sociedade dos mortos, bem como o fato de saber que pode reconstruir sua história, ter um trabalho, casar e seguir em frente são possibilidades que integra Dick à Mortópolis, sendo assim, essa centelha em destaque é o fio da vida que se sobrepõe ao manto da morte. É a ligação entre o mundo dos vivos e o dos mortos, significando espaços plurais representados através da imagem. A centelha é a aura da narrativa.

Retomamos, aqui, a construção da imagem na narrativa de Luís Dill, que neste ponto nos dá uma proporção do todo, uma vez que esse azul destaca-se em amplo espaço em preto e branco. A criação da imagem possui a influência do efeito cut out, elemento estético da linguagem fotográfica, que consiste em deixar a imagem em preto e branco, gerando duas camadas de cor no histórico da figura, no intuito de resgatar um ponto, em cor, na imagem que está em baixo, ou seja, de resgatar algum tom que está por baixo do preto e branco. Esse tipo de recurso é encontrado em photoshop e aplicativos (editores de imagem) espécies de ferramentas muito utilizadas por jovens, para enaltecer o melhor foco nos seus registros diários de selfie.

A releitura da linguagem fotográfica que Dill faz, através da Literatura, diz respeito ao espaço imagética que o sujeito está inserido, especificamente na contemporaneidade. Pellegrini (1999) menciona que na era imagética nada há mais o que se fazer, pois nada parece necessário, porque o mundo da imagem dá tudo ao fruidor. $\mathrm{O}$ ser humano envolve-se com a imagem numa espécie de fetiche e experiências desenfreadas de registrar tudo por meio da imagem. O público jovem é refém e produtor 
dessa influência da cultura de massa, já que a era selfie nos mostra sempre mais do mesmo, há uma padronização em filtros utilizados em posses e momentos.

Todavia, o escritor gaúcho, transcende essa expectativa, já que ele dá uma nova leitura ao recurso da linguagem fotográfica, por meio da palavra. Há um desafio embutido para o leitor, que indica perspectivas simbólicas voltadas ao diálogo da imagem e do tema. Nessas entrelinhas, podemos dizer, nesse entre espaço, que a magia "do como" se contar e "de como" se apropriar efetivam-se, já que a riqueza cósmica da vida exterior e suas influências midiáticas transbordam em imagens (palavras) na narrativa de Luís Dill.

Por meio desses diálogos, o desfecho da aventura de Dick se dá pela integração total do garoto à Mortópolis. O narrador coloca o leitor em expectativa e por meio de casos não contados, que configuram as digressões na obra, transmite o sentido de que Dick pode voltar ao mundo dos vivos, mas ele não volta, a morte cai bem ao jovem e ele aceita-a. Notamos isso no seguinte trecho:

Necessitava, claro, de respostas, muitas respostas. Mas, como estava morto, teria um longo tempo para responder a todas elas. Ou ali se envelhecia também?

A penumbra começou a ceder. Logo outra noite avançaria sobre Mortópolis. E Roneldick Silva se lembrou da garota de olhos azuis. Ela ainda tinha uma lenda para lhe contar.

A chuva das $17 \mathrm{~h} 29$ começou. (DILL, 2016, p. 155).

Mesmo se tratando de um desfecho a narrativa tem um aspecto contínuo, como por exemplo, de uma saga. O narrador deixa brechas na história, que remete a um efeito contínuo, a saber: a vida de Dick antes de sua morte, seu assassinato e a lenda, que possivelmente, o envolve. A personagem está repleta de questionamentos, assim como o leitor que fica na expectativa de uma continuação.

\section{Para concluir}

A cultura de massa pode propiciar grandes obras literárias, no entanto, torna-se uma grande problemática quando pensada no mundo acadêmico. $\mathrm{O}$ ser aqui e agora dessa cultura traz uma carga semântica e simbólica por natureza, o sujeito contemporâneo não tem distanciamento espacial e temporal do fenômeno que é a cultura de massa. Antes de tudo, como bem cita Eco ( 2001) a cultura de massa é uma cultura e, portanto, precisa ser levada a sério, precisa ser tratada com o mesmo rigor de análise das obras voltadas para uma cultura erudita, pois ela foi difundida entre as massas, contexto natural, de uma sociedade industrializada.

A questão da homogeneização coloca uma obra literária em vias de acesso e de democratização do produto, possibilitando uma maior interação entre os receptores. No campo de produção, o escritor sofre diversas influências, principalmente, das novas tecnologias, mas isso não simboliza a diminuição do seu valor estético e qualitativo da sua obra. Luis Dill, por exemplo, é um escritor contemporâneo, que consegue apropriarse de elementos estéticos da indústria cultural e aplicá-los em suas obras de forma desafiadora para o leitor, possibilitando-lhe uma aprendizagem.

De acordo com Candido (2000) só podemos entender uma obra a partir de uma interpretação dialética entre a fusão de texto e contexto. O social, torna-se assim, um fator determinante no processo interpretativo, no entanto, não é o único passível de 
significação, pois tal elemento, que está no campo externo à obra, desempenha uma função na constituição da estrutura, tornando-se também interno.

Esse processo pode ser contemplado na narrativa de Luís Dill quando nos deparamos com sujeitos contemporâneos inseridos em uma sociedade imagética, tendo em vista que a maioria das mídias sociais se beneficia e induze o uso da imagem como principal forma de comunicação e identificação. Dill traz isso para o campo interno, quando constrói o cosmo imagético da sua narrativa em preto e branco, com apenas um tom sobressaindo, o azul. Eis aí um desafio para o escritor, construí um mundo representativo da realidade que tenha um valor estético, que promulgue significação e formação do ser humano.

É com esse traço estético que Luís Dill consegue prender o leitor, que não se destina o somente ao jovem, mas ao próprio adulto. A temática da morte é trabalhada de forma leve e humorística envolve a todos e há uma mensagem simbólica que cada fruidor, a partir de seu percurso social e cultural, pode significar.

\section{REFERÊNCIAS}

BENJAMIN, W. A obra de arte na era de sua reprodutibilidade técnica. 1955. In.: ADORNO et al. Teoria da cultura de massa. Comentários e seleção de Luiz Costa Lima. São Paulo: Paz e Terra, 2000. p. 221-254.

CANDIDO, Antonio. O escritor e público/Crítica e sociologia. In.: Literatura e sociedade. 9 ed. São Paulo: Editora Nacional, 1980.

DEVES, Maristela S. Entrevista com Luís Dill. 2011. In.: Revista Samizdat. Disponível em: < http://www.revistasamizdat.com/2009/09/entrevista-com-luisdill.html\#comment-form>. Acesso em 05 de jan. de 2016.

DILL, Luís. Dick Silva - no mundo intermediário. São Paulo: Editora Pulo do Gato, 2016.

ECO, Umberto. Cultura de massa e níveis de cultura. In.: Apocalípticos e integrados. 6 ed. São Paulo: Perspectiva, 2001. p. 33-67.

Pós-escrito a Nome da Rosa. Rio de Janeiro: Nova Fronteira, 1985. p. 07-66.

HORKHEIMER, Max; ADORNO, Theodor. A indústria cultural: o iluminismo como mistificação de massas. In. LIMA, Luiz Costa. Teoria da cultura de massa. São Paulo: Paz e Terra, 2002. p. 169-214.

LANGLADE, Gérard. O Sujeito leitor, autor da singularidade da obra. Trad. Rita Jover-Faleiros. In: ROXEL, Annie; LANGLADE, Gérard; REZENDE, Neide Luzia de. Leitura subjetiva e ensino de literatura. São Paulo: Alameda, 2013.

MACDONALD, Dwight. Massicultura e Medicultura. In: ECO, Umberto et al. A indústria da cultura. Lisboa: Meridiano; 1971, p. 67-149.

MARTHA, Alice Áurea Penteado. O insólito como efeito discursivo. In.: CECCANTINI, João Luís; VALENTE, Thiago Alves. Narrativas juvenis e mediações de leitura. São Paulo: Cultura Acadêmica; SP: ANEP, 2015. 
MORIN, Edgar. A integração cultural. In.:

Cultura de massas no século XX:

o espírito do tempo V. I. Neurose. 4 ed. Rio de Janeiro: Forense Universitária, 1977. p. $11-85$.

O cinema ou o homem imaginário. Lisboa: Relógio D’Água, 1997.

REDE ARTÍSTAS GAÚCHOS. Luís Dill. 2015. Disponível em: < http://www.luisdill.com.br/>. Acesso em 10 de jan. de 2016.

THOMPSON, John B. Introdução. In.: Mercadores de cultura. São Paulo: Editora Unesp, 2013. p. 07-32.

VILLAS BOAS \& MOSS. Luís Dill. 2016. Disponível em: < http://vbmlitag.com.br/index.php/project/luis-dill/>. Acesso em 20 jan. 2016.

Recebido em 18 de outubro de 2018

Aceito em 19 de dezembro de 2018 